\title{
DESIGNING LISTENING TASKS FOR ENGLISH STUDENTS
}

\author{
Darwissyah Irwan D, Nunun Indrasari \\ UNU Lampung \\ Corresponding email: darwissyah@unu.ac.id
}

\begin{abstract}
Listening skill is one of important skills in learning English. Therefore, it is considered as difficult skill for the students. Designing tasks for listening skill is also challenging for the teachers. This paper describes possible ways in designing listening tasks for the students. The descriptions include definition, the types of tasks, and the possible ways of designing task for listening skills based on the types of listening performance.
\end{abstract}

Key words: designing task, listening skill, listening tasks

\section{A. INTRODUCTION}

Brown(2000) says that Teaching is showing or helping someone to learn how to do something, giving instructions, guiding in thr study of something, providing with knowlege, causing to know or understand. Teaching and learning English should concern more on mastering English communication. The learning objectives of the English language programs should cover language skills (listening, speaking, reading, and writing). From those four skills, listening is considered as the key of a communication. According to Nation, listening is the natural precursor to speaking; the early stages of language development in a person's first language (and in naturalistic acquisition of other languages) are dependent on listening. If the listeners don't understand about what they listen, the communication will get a problem. It can be said that when the students got difficulties in listening, they may have problems in speaking, even in reading and writing. 
Listening is one of the English skills that has an important role in English language program. Therefore, an English students need to develop listening skills and listening strategies to become proficient in listening. According to Brown, one of micro skills in listening, as follows:

1. Retain chunks of language of different lengths in short-term memory.

2. Discriminate among the distinctive sounds of English.

3. Recognize English stress and patterns, words in stressed and unstressed positions, rhythmic structure, intonational contours, and their role in signaling information.

4. Recognize reduced forms of words.

5. Distinguish word boundaries, recognize a core of words, and interpret word order patterns and their significance.

6. Process speech at different rates of delivery.

7. Process speech containing pauses, errors, corrections, and other performance variables.

8. Recognize grammatical word classes (nouns, verbs, etc.), systems (e.g., tense, agreement, pluralization), patterns, rules, and elliptical forms.

9. Detect sentence constituents and distinguish between major and minor constituents.

10. Recognize that a particular meaning may be expressed in different grammatical forms.

11. Recognize cohesive devises in spoken discourse.

12. Recognize the communicative functions of utterances, according to situations, participants, goals.

13. Infer situations, participants, goals using real-world knowledge.

14. From events, ideas, etc., described, predict outcomes, infer links and connections between events, deduce causes and effects, and detect such relations as main idea, supporting idea, new information, given information, generalization, and exemplification. 
15. Distinguish between literal and implied meaning.

16. Use facial, kinetic, body language, and other nonverbal clues to decipher meaning.

17. Develop and use a battery of listening strategies, such as detecting key words, guessing the meaning of words from context, appeal for help, and signaling comprehension or lack thereof.

By concerning on these micro skills of listening, also the teachers or lecturers can easily design the objective of the learning program.

In teaching listening, lecturers have several responsibilities in helping their students to become proficient in listening. Murcia (2001:99) describes teachers' responsibilities as follows. First, lecturers must understand the role of listening in language learning in order to utilize listening in ways that facilitate learning. Second, they must understand the complex interactive nature of the listening process and the different kind of listening that learners must do in order to provide students with appropriate variety and range of listening experiences. In this case, lecturers must be careful in setting appropriate goals for different levels of proficiency; choosing listening materials; incorporating support materials such as visual aids into listening tasks and combining listening with other skills. Finally, lecturers must understand how listening skills typically develop and must be able to assess the stage of listening at which their students are, so that each student can engage in the most beneficial types of listening activities given based on his or her level of proficiency.

As stated by Murcia, selecting listening materials is one of lecturers' responsibilities when planning a lesson. Designing listening materials is not a simple work since they should find sources which are relevant with the learning objectives and the students' need. This paper aims at describing the principle of appropriate listening tasks and proposes some possible tasks for learning listening. 


\section{B. THEORETICAL REVIEW}

\section{Concept of Listening}

Myers and Myers (1992: 43) state that listening is considered not only hearing, but also including the added dimensions of understanding, paying overt attention, analyzing, and evaluating the spoken messages, and possibly acting on the basis of what has been heard. Listening is not a one-way street. It is not merely the process of a unidirectional receiving of audible symbols (Brown, 2000:249). It means, listening is an active process of converting meaning from spoken language. It can be said that listening is more than merely hearing, but there is an active process inside the brain.

\section{Types of Listening Performance}

There are some types of listening performance according to Brown (2000:255) as follows:

1. Reactive: It requires little meaningful processing. The role of listener as merely a "tape recorder" must be very limited. The only role that reactive listening can play in an interactive classroom is individual drills that focus on pronunciation.

2. Intensive: It focuses on components (phonemes, words, intonation, discourse markers, etc.) in its requirement that students single out certain elements of spoken language. It includes the bottom-up skills that are important at all levels of proficiency.

3. Responsive: A significant proportion of classroom listening activity consists of short stretches of teacher language designed to elicit immediate responses.

4. Selective: Its purpose is not to look for the global or general meanings, necessarily, but to be able to find important information in a field of potentially distracting information.

5. Extensive: Its purpose is to develop a top-down, global understanding of spoken language. 
6. Interactive: This listening activity can include all five of the above types as learners actively participate in discussions, role-plays, and other pair and group work. It must be integrated with speaking (and perhaps other) skills in the authentic give and take of communicative interchange.

\section{Exercise Type for Interactive Listening}

Lecturers need to consider alternative exercise types, which can take a number of forms. Field (2009:70) suggests some, which might be applied to either scripted or authentic materials, as follows:

\section{Modelling.}

Dialogue material for non-participatory listening provides the teacher with useful models of conversation structure, especially where the recordings are authentic. After checking understanding in the traditional way, the teacher might go on to draw attention to some of the following, with interactive situations in mind:

a. how changes of turn are signaled;

b. the links between one turn and another; how changes of topic are marked;

c. any examples of repair strategies;

d. any examples of back-channeling where the listener signals that she has understood and is still listening;

e. any examples of accommodation, where the listener echoes the vocabulary or grammar of the speaker;

f. any examples of pauses in the conversation where the listener can gain processing time.

2. Paused Practice.

Instead of presenting a listening dialogue for overall comprehension, the teacher pauses the recording after each turn of the first speaker and asks learners to anticipate the response of the second. The technique is especially 
apt where the dialogue follows a consistent pattern of 'question-answer' or 'initiate-respond'.

Clearly, in the early stages there are bound to be long delays while learners construct their replies. It thus makes sense to develop the exercise in a graded way: with listeners first learning to interpret short turns quite rapidly, later going on to discuss possible responses and finally formulating their own responses under time pressure. As learners become more proficient, they should be encouraged to compare their responses critically with those that occur in the recording, checking both for appropriateness and for accuracy.

3. Quick-fire questions.

The recording consists of a series of interview questions (possibly about the learner's own life and interests), to which the learner has to give short and immediate replies within a tightly controlled time frame. This exercise is especially suitable for intensive practice in a listening center, where the learner can record, check and revise responses.

4. Rehearsal.

Successful L2 learners often anticipate encounters in L2 by constructing in their minds a range of possible sentences that they might need. The process, known as rehearsal, involves a kind of 'voice in the head'. It can be used to predict both questions and responses, thus improving performance in person-to-person exchanges.

5. Jigsaw listening.

A simple listening exercise scrambles the turns in a recorded dialogue. Those of the first speaker are grouped together in random order and tagged a, b, c, d; those of the second speaker are similarly randomized and tagged 1, 2, 3, 4. Learners listen several times. They first match each initiating turn with its response; they then decide on a likely order for the pairs of utterances they have identified. This exercise works well in sensitizing learners to the 
relationship between turns; but, because the medium is purely an oral one, the number of turns has to be limited to (say) a maximum of ten to avoid excessive demands on memory.

6. Recording.

Video recording is used very frequently to monitor the performance of teachers, but rather less to monitor that of learners. Any type of language lesson which uses L2 as the medium of instruction provides a good example of the kind of short-turn interaction that the listening teacher needs to practice. It is thus worthwhile recording learners' performance in a class and replaying short sections for them to discuss (a) moments where their understanding broke down and why; and (b) responses which were inappropriate and why.

7. Communicative tasks.

All too often, the outcomes of communicative tasks are evaluated in terms of either the effectiveness of oral production or the achievement of a particular target. Too little attention is given to the role of listening, though it is clearly an equal partner with speaking in this type of activity. From time to time, it is worthwhile to set up an information gap task in the listening classroom and (either through video recording or through observation) to monitor:

a. the extent to which listening skills are successfully used;

b. the use made by learners of repair and back-channeling;

c. the causes and effects of misunderstanding.

Moreover, Richard (2008: 6) mentions the examples of the kinds of tasks that develop bottom-up listening as follows:

1. Identify the referents of pronouns in an utterance

2. Recognize the time reference of an utterance

3. Distinguish between positive and negative statements

4. Recognize the order in which words occurred in an utterance 
5. Identify sequence markers

6. Identify key words that occurred in a spoken text

7. Identify which modal verbs occurred in a spoken text

Furthermore, Ellis and Brewster (1992: 57) state some listening strategies in listening a story as follows.

1. Predicting: it is useful to encourage children to predict what they think might come next in a story.

2. Inferring opinion or attitude: An awareness of stress, intonation and body language-such as facial expressions or gesture- will help the children work out if a character is angry, happy, sad and so on. This contributes to understand the story.

3. Working out from context: Although keywords might be glossed before the story is told, children need to be encouraged to use pictures and their general knowledge about a topic to work out the meaning of unfamiliar words.

4. Recognizing discourse patterns and markers (such first, then, finally, or: but, then, so) gives important signals about what is coming next in a story.

\section{LISTENING TASKS DESIGN}

\section{Intensive Listening Task}

1. Recognizing the Phonological and Morphological Elements

This task is for recognizing the phonological and morphological elements of language, includes recognizing consonants in phonemic pairs, recognizing vowels in phonemic pairs, recognizing -ed ending in morphemic pairs, recognizing stress pattern in the word "can't", and one-word stimulus Example:

The student hear : "He's from California"

The students read: "He's from California"

"She's from California" 
1. Paraphrase Recognition

This task provides the sentence/dialog stimulus then asks the students to choose the correct paraphrase from a number of choices.

Example:

The students hear: "Helloe, My name is Keiko. I come from Japan"

The students read : a. Keiko is comfortable in Japan

b. Keiko wants to come to Japan

c. Keiko is Japanese

d. Keiko likes Japan

\section{Responsive Listening Tasks}

This task provides the stimulus of questions then asks the students to respond the appropriate answer. The answer can be cloze-ended or open-ended response.

\section{Selective Listening}

\section{Listening Cloze}

In listening cloze tasks, the students should listen to a

story/monolog/conversation while reading the written text in which selected

words or phrases have been deleted. The students see the transcript of the passage they are listening to and fill in the blanks with the words/phrases they hear.

2. Information transfer

This task encourages the students to transfer the information from the audio to a visual representation such as labeling a diagram, identifying an element in a picture, etc.

Here is the example of multiple-picture-cued selection. 


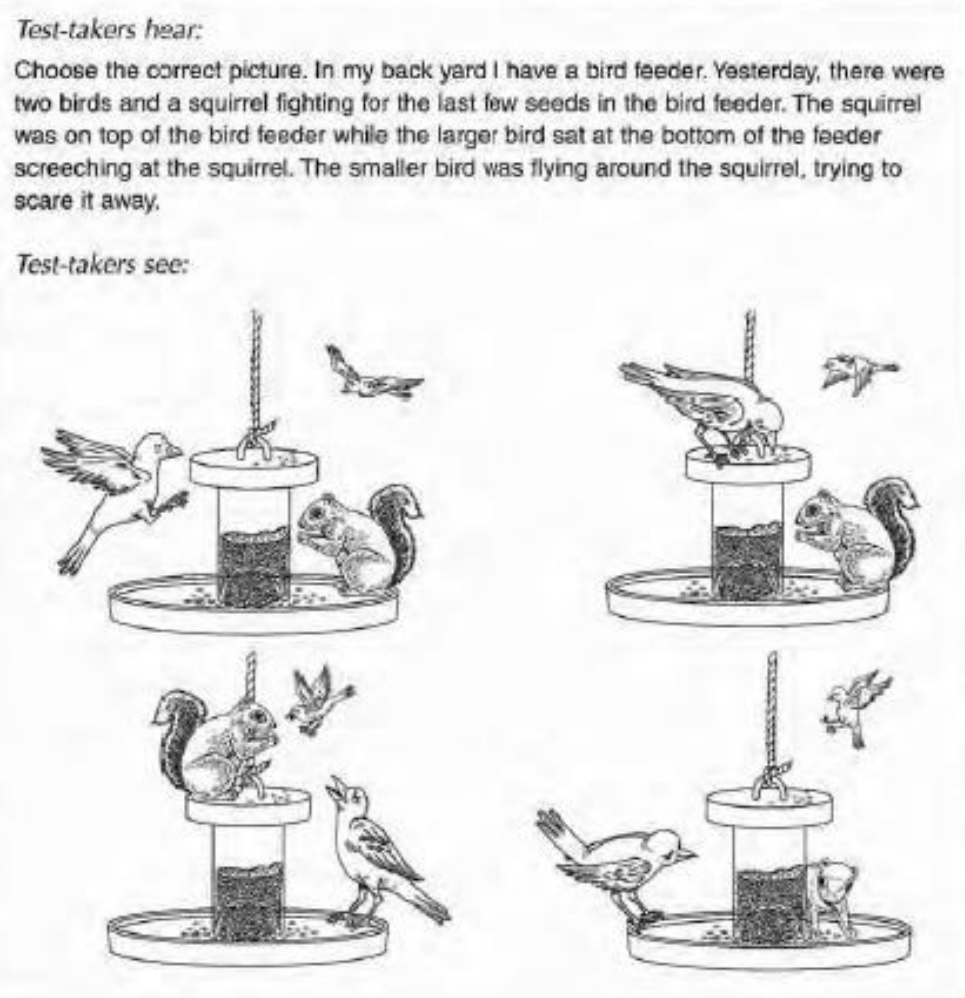

\section{Extensive Listening}

1. Communicative Stimulus-Response Task

In this task, the student is presented with the long monolog or conversation then is asked to respond to a set of comprehension questions

2. Authentic Listening Task

Authentic listening tasks provide real-world context of listening performance. In this task, there are some possible activities can be done for the students, such as note taking, editing, or retelling the recording that the students hear. 


\section{CONCLUSION}

Designing listening tasks is not a simple way. In designing the tasks, the teacher should consider the types of listening performance in order to match the instrument of the task with the learning objectives. Teacher should also concern more on what aspects/micro skills that the teacher wants to measure through the task.

\section{E. REFERENCES}

Brown, D. 2000. Teaching by Principles. New Jersey: Prentice Hall.

Brown, D. 2003. Language Assessment Principle and Classroom Practice. San Francisco: Longman

Brown, Steven. (2006). Teaching Listening . Cambridge: Cambridge University Press.

Celce-Murcia, Marianne. (2001).Teaching English as a Second or Foreign Language. $3^{\text {rd }}$ edition. Boston: Heinle \& Heinle

Ellis, G \& Brewster, J. 1992. The Primary English Teacher's Guide. Harmondswath: Penguin Book

Nation, I. S. P. \& Newton, J. (2009). Teaching ESL/EFL Listening and Speaking. New York: Routledge.

Oxford, R. L. (1993). Research Update on Teaching L2 Listening. System,21,205211

Richard, J. 2008. Teaching Listening and Speaking. Cambridge : Cambridge University Press. 